\title{
A background infusion of morphine enhances patient-controlled analgesia after cardiac surgery
}

\author{
[Une perfusion de morphine améliore l'analgésie autocontrôlée après \\ cardiochirurgie]
}

Tayfun Guler MD, Hakki Unlugenc MD, Zehra Gundogan MD, Mehmet Ozalevli MD, Okan Balcioglu MD, Mehmet Sah Topcuoglu MD

Purpose: We compared the efficacy of patient-controlled analgesia (PCA), with or without a background infusion of morphine, on postoperative pain relief in patients extubated in the operating room after coronary artery bypass grafting (CABG) surgery.

Methods: With Faculty Ethics approval, 60 consenting adults undergoing elective coronary artery surgery were randomly assigned to receive either morphine PCA alone (group PCA-A, $n=$ 30) or morphine PCA plus a background infusion (group PCA-B, $n$ $=30$ ) for $24 \mathrm{hr}$ postoperatively. Pain scores with verbal rating scale (VRS; from 0 to 10) at rest, sedation scores, morphine consumption and delivery/demand ratios were assessed at zero, one, two, four, six, 12 and $24 \mathrm{hr}$ after surgery. Hemodynamic variables and arterial blood gases were also recorded in the same periods.

Results: Sedation scores in the two groups were similar. At all study periods after the first postoperative hour, VRS remained below 5 in both groups. Pain scores were significantly lower in the background infusion group, which also had greater cumulative morphine consumption (61.7 $\pm 10.9 \mathrm{mg}$ vs $38.5 \pm 16.2 \mathrm{mg}$ ). There were no episodes of hypoxemia or hypertension.

Conclusion: Morphine PCA effectively controlled postoperative pain after cardiac surgery. The addition of a background infusion of morphine enhanced analgesia and increased morphine consumption.

Objectif: Nous avons comparé les effets de l'analgésie autocontrôlée (AAC), avec ou sans une perfusion de morphine de base, sur l'analgésie postopératoire des patients extubés au bloc opératoire à la suite d'un pontage aortocoronaire.

Méthode : Soixante adultes consentants devant subir une opération de pontage aortocoronaire réglée ont été recrutés dans notre étude après l'accord du Comité d'Éthique de la Faculté. Les patients ont reçu soit de la morphine en AAC seule (Groupe AAC-A, $n=30$ ), soit de la morphine en $A A C$ plus une perfusion de base continue (Groupe $A A C-B, n=30$ ) pendant $24 \mathrm{~h}$ après l'opération. La douleur au repos selon une échelle verbale analogique (score de 0 à 10), les scores de sédation, la consommation de morphine, ainsi que les niveaux sériques de morphine à zéro, une, deux, quatre, six, 12 et 24 h après l'opération ont été évalués. Le bilan hémodynamique et les gaz du sang ont aussi été enregistrés durant la même période.

Résultats : Il n'y avait pas de différence dans les scores de sédation entre les deux groupes. Après la première heure postopératoire l'échelle verbale analogique était en dessous de 5 dans les deux groupes. Les scores de douleurs étaient significativement moins élevés dans le groupe perfusion de base; ce dernier groupe avait aussi une plus grande consommation cumulative de morphine (61,7 $\pm 10,9 \mathrm{mg}$ vs 38,5 \pm 16,2 mg). II n'y a pas eu d'épisode d'hypoxie ni d'hypertension.

Conclusion : L'AAC avec la morphine réduit efficacement la douleur postopératoire en cardiochirurgie. L'ajout d'une perfusion de base de morphine améliore l'analgésie et augmente la consommation de morphine.

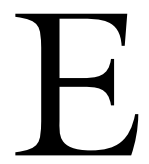

ARLY extubation after cardiac surgery is an important part of fast-track cardiac anesthesia. Immediate extubation is usually safe ${ }^{1}$ if good analgesia can be achieved. ${ }^{1-4}$ Although the use of patient-controlled analgesia (PCA) is well established for major abdominal and orthopedic surgeries, ${ }^{3-6}$ little has been published about its use after cardiac surgery. ${ }^{7-13}$ Conventional bolus PCA may be less effective because of disorientation in the intensive care unit (ICU) environment, and poor retention of preoperative learning. ${ }^{11}$ The addition of a background morphine infusion to morphine PCA may improve patient analgesia and comfort.

From Departments of Anaesthesiology and Cardiovascular Surgery, Cukurova University, School of Medicine, Adana, Turkey.

Address correspondence to: Dr. Tayfun Guler, Cukurova University, School of Medicine, Department of Anaesthesiology, 01330, Balcali,

Adana, Turkey. Phone: + 9053235722 24; Fax: + 9032233867 42; E-mail: tayguler@cu.edu.tr Accepted for publication January 22, 2004.

Revision accepted April 14, 2004. 
This prospective, randomized clinical study was designed to test the hypothesis that adding a standardized background morphine infusion to morphine PCA would improve postoperative analgesia without increasing morphine consumption or side effects, in patients extubated in the operating room after coronary artery surgery.

\section{Methods}

\section{Patients and procedures}

Following Faculty Ethics Committee approval and informed patient consent, 60 patients undergoing elective coronary artery bypass grafting (CABG) surgery were recruited. Preoperative exclusion criteria were age $>70 \mathrm{yr}$, emergency surgery, previous CABG or heart valve surgery and poor left ventricular function (ejection fraction $<40 \%$ ). Postoperative exclusion criteria included surgical re-exploration, hemodynamic instability including the occurrence of serious arrhythmias, bleeding, postoperative mental confusion, and failure of the patient to properly use the PCA pump. Hemodynamic instability was defined as systolic blood pressure (SBP) less than $90 \mathrm{mmHg}$ with ongoing dopamine $\left(>5 \mu \mathrm{g} \cdot \mathrm{kg}^{-1} \cdot \mathrm{min}^{-1}\right)$ or adrenaline infusion, or transfusion of more than four units of packed cells in the first two postoperative hours.

Patients received their usual cardiac medication preoperatively. All were instructed preoperatively on the use of the PCA device, with instruction booklets and bedside discussions. They were also instructed on the use of the verbal rating scale (VRS) for the measurement of postoperative pain. ${ }^{6}$

\section{Anesthetic protocol}

Patients were premedicated with im morphine sulphate, $0.1 \mathrm{mg} \cdot \mathrm{kg}^{-1}, 30 \mathrm{~min}$ before surgery. Anesthesia was induced with $i v$ propofol $0.5 \mathrm{mg} \cdot \mathrm{kg}^{-1}$ and remifentanil $0.5 \mu \mathrm{g} \cdot \mathrm{kg}^{-1}$ in all patients. Neuromuscular relaxation was induced by vecuronium $0.1 \mathrm{mg} \cdot \mathrm{kg}^{-1}$, and maintained by a bolus administration of $0.03 \mathrm{mg} \cdot \mathrm{kg}^{-1}$ at 30 min intervals. After intubation, anesthesia was maintained with propofol $\left(0.5-2.0 \mathrm{mg} \cdot \mathrm{kg}^{-1} \cdot \mathrm{hr}^{-1}\right)$ and remifentanil $\left(5-20 \mu \mathrm{g} \cdot \mathrm{kg}^{-1} \cdot \mathrm{hr}^{-1}\right)$. Ventilation with an oxygen/nitrous oxide mixture was controlled, at a tidal volume of $10 \mathrm{~mL} \cdot \mathrm{kg}^{-1}$ and a respiratory rate of 10 breaths. $\mathrm{min}^{-1}$, to produce an end-tidal carbon dioxide partial pressure of about $40 \mathrm{mmHg}$.

\section{Surgical protocol}

Surgery was performed in a standard fashion through a median sternotomy with saphenous veins and internal thoracic arteries harvested as conduits. A standard crystalloid prime was used in the cardiopulmonary bypass (CPB) circuit. Myocardial protection was achieved with intermittent, antegrade, warm blood cardioplegia. Non-pulsatile CPB flow was maintained between 1.5 and $2 \mathrm{~L} \cdot \mathrm{min}^{-1} \cdot \mathrm{m}^{-1}$ using a membrane oxygenator. Patients were not actively cooled, but their core temperature was allowed to drift to 32 to $34^{\circ} \mathrm{C}$. Active rewarming to $37^{\circ} \mathrm{C}$ was completed before aortic cross-clamp removal.

\section{Extubation protocol}

Fifteen minutes before the end of surgery, muscle relaxation was reversed with iv neostigmine, 0.05 $\mathrm{mg} \cdot \mathrm{kg}^{-1}$ and atropine sulphate, $0.01 \mathrm{mg} \cdot \mathrm{kg}^{-1}$. All patients were extubated in the operating room when awake, and were cooperative and normoventilating when transferred to the cardiovascular care unit. Postoperatively, forced air warming was used to maintain body temperature between $36.5^{\circ}$ and $37.5^{\circ} \mathrm{C}$.

\section{Postoperative analgesia}

Postoperative analgesia was started just before sternal closure with a standardized loading dose of morphine sulphate, $0.15 \mathrm{mg} \cdot \mathrm{kg}^{-1}$ via a PCA device (Abbott Acute Pain Manager-APM, Pain Manager Provider, North Chicago, IL, USA). After extubation, patients were randomly allocated into either the PCA alone group (PCA-A, $n=30$ ) or PCA plus continuous background infusion group (PCA-B, $n=30$; random number table generated by a computer program). Each code was indicated on a data form sealed in an envelope and opened by the anesthesiologist.

After arrival at the cardiovascular care unit, both groups were allowed to use supplemental bolus PCA doses, $0.015 \mathrm{mg} \cdot \mathrm{kg}^{-1}$, with a lockout time of $15 \mathrm{~min}$. In addition, Group PCA-B received a standardized background infusion, $0.03 \mathrm{mg} \cdot \mathrm{kg}^{-1} \cdot \mathrm{hr}^{-1}$. PCA was discontinued after $24 \mathrm{hr}$. Patients complaining of pain despite PCA therapy also received supplemental morphine doses of $0.01 \mathrm{mg} \cdot \mathrm{kg}^{-1}$. The study started at time 0 , immediately after extubation. Scores for pain, sedation and hemodynamic variables SBP, diastolic blood pressures, heart rate and peripheral oxygen saturation $\left(\mathrm{SpO}_{2}\right)$ were recorded at zero, one, two, four, six, 12 and $24 \mathrm{hr}$ postoperatively. Morphine consumption was assessed at the same intervals. Supplementary morphine and any side effects (such as nausea, vomiting, cough suppression, constipation, urinary retention and pruritus) associated with the procedure were also recorded.

Pain was assessed by a VRS from 0 to $10(0=$ no pain, $10=$ the worst pain imaginable) and sedation on a six-point scale described by Ramsay et al. $(1=$ anxious and agitated or restless or both; $2=$ cooperative, oriented, tranquil; 3 = responds to commands only; 4 
TABLE I Patient characteristics, duration of surgery, time to extubation and the number of patients requiring supplemental morphine

\begin{tabular}{lll}
\hline & $\begin{array}{l}\text { Group PCA-A } \\
(n=25)\end{array}$ & $\begin{array}{l}\text { Group PCA-B } \\
(n=25)\end{array}$ \\
\hline Age $(\mathrm{yr})^{*}$ & $55.9(50.4-61.4)$ & $57.4(51.2-63.5)$ \\
Sex M/F $(n)$ & $19 / 6$ & $20 / 5$ \\
Weight $(\mathrm{kg})^{*}$ & $74.4(64.5-84.2)$ & $68.2(61.9-74.6)$ \\
Duration of surgery $(\mathrm{min})^{*}$ & $263.0(242.2-283.7)$ & $289.6(275.4-303.8)$ \\
Time to extubation $(\mathrm{min})^{*}$ & $7.3(4.4-10.2)$ & $5.8(3.4-8.1)$ \\
$\begin{array}{l}\text { Number of patients requiring } \\
\text { supplemental morphine }(n)\end{array}$ & 3 & - \\
\hline
\end{tabular}

*Data are presented as mean ( $95 \%$ confidence interval). There was no statistical difference between groups.

= brisk response to a light glabellar tap or loud auditory stimulus; 5 = sluggish response to a light glabellar tap or loud auditory stimulus; $6=$ no response to light glabellar tap or loud auditory stimulus). ${ }^{14}$

\section{Statistical analysis}

The primary endpoint was defined as a reduction in VRS scores throughout the procedures, a $30 \%$ reduction being regarded as clinically significant. The sample size was determined by power analysis; with a power of 0.8 and significance level of $0.05,22$ subjects per study group were required. Statistical analyses were performed using the statistical package SPSS v 10.0 (SPSS Inc., Chicago, IL, USA). Normality was checked for each continuous variable. For between-group comparisons the Student's t test was used for normally distributed variables, and the Mann-Whitney $U$ test for non-normally distributed data. Time dependent data within groups were analyzed by repeated measure analyses. Friedman's and Wilcoxon's rank sum tests were used to evaluate the differences compared to baseline. The incidence of complications between the groups was analyzed by the Chi-square test. Data were reported as mean $(95 \%$ confidence interval) or median $(\min -\max )$ and $P$ value < 0.05 was accepted as statistically significant.

\section{Results}

Sixty patients were enrolled in the study. Five in each group were excluded because of hemodynamic instability and reoperation. Patient characteristics, duration of surgery, time to extubation and the number of patients requiring supplemental morphine were comparable between groups (Table I). There were no differences between groups in sex, age, height and weight. There were no significant differences in $\mathrm{SpO}_{2}$ values between groups, and no great variations or dif- ferences in hemodynamic data, values remaining within the normal range throughout the study period.

Postoperative pain was treated successfully in both groups. Both time and treatment affected VRS $(P<$ 0.05 ). After the PCA was started, VRS scores decreased significantly with time in both groups $(P<0.05)$ and were significantly lower at each study period $(P<0.05)$. Mean pain scores were significantly lower in the PCA plus infusion group at two, four, six, 12 and $24 \mathrm{hr}$ (Table II); $(P<0.05)$.

Cumulative morphine consumption differed significantly between groups. Patients given a background infusion consumed about $60 \%$ more morphine in the first $24 \mathrm{hr}(61.7 \pm 10.9 \mathrm{mg}$ vs $38.5 \pm 16.2 \mathrm{mg}: P<$ 0.05 ). Cumulative morphine consumption was significantly greater at two, four, six, 12 and $24 \mathrm{hr}$ with the background infusion (Table II). In spite of this, there were no significant differences in mean sedation scores between groups at any study period, including before the PCA was started (Table II). Sedation was only affected by time; it decreased significantly with time in both groups $(P<0.05)$.

Three patients in group PCA-A complained of pain and were given a single iv dose of morphine $(0.01$ $\mathrm{mg} \cdot \mathrm{kg}^{-1}$ ). Five (two in PCA-A, and three in PCA-B) experienced nausea and received a single $4 \mathrm{mg} i v$ dose of ondansetron. There were no significant differences between groups in the incidence of postoperative nausea. Other side effects were mostly minor (Table III).

\section{Discussion}

After cardiac surgery, stable hemodynamics, low myocardial oxygen consumption and freedom from ischemic events are essential. Thus, immediate extubation requires effective postoperative analgesia. ${ }^{1}$ The use of morphine PCA for the treatment of postoperative pain after major surgery is well described, ${ }^{7-13}$ but there is little specifically dealing with extubation in the operating room after coronary artery surgery, as in our study. We found that adding a background morphine infusion to a standard morphine PCA improved postoperative analgesia without increasing side effects.

After coronary artery bypass surgery, PCA gives better pain control than traditional nurse-controlled analgesia according to Pettersson et al. ${ }^{9}$ and Boldt et al., ${ }^{10}$ although this was not confirmed by Tsang et al. ${ }^{11}$ Another recent study showed no improvement in pain control or neurohumoral response in patients extubated in the operating room after CABG surgery. ${ }^{15}$ Background opiate infusions increase morphine consumption and sedation, and thus can increase the incidence of respiratory depression. ${ }^{4,5}$ However they may be beneficial in cardiac surgery patients who have greater 
TABLE II Pain scores (verbal rating scale), sedation scores, and cumulative morphine consumption in groups at zero, one, two, four, six, 12 and $24 \mathrm{hr}$ after PCA administration

\begin{tabular}{|c|c|c|c|c|c|c|c|}
\hline & 0 hour & $1^{s t}$ hour & $2^{\text {nd }}$ hour & $4^{\text {th }}$ hour & $\sigma^{\text {th }}$ hour & $12^{\text {th }}$ hour & $24^{\text {th }}$ hour \\
\hline \multicolumn{8}{|l|}{ Pain scores } \\
\hline Group PCA-A & $8(0-10)$ & $6(0-8) \dagger$ & $5(0-7) \dagger$ & $4(1-6) \dagger$ & $4(1-6) \dagger$ & $4(0-5) \dagger$ & $4(0-5) \dagger$ \\
\hline Group PCA-B & $8(0-10)$ & $5(0-8) \dagger$ & $4(0-7)^{*} \dagger$ & $2(0-6)^{*} \dagger$ & $1(0-4)^{*} \dagger$ & $0(0-3)^{*} \dagger$ & $0(0-3)^{*} \dagger$ \\
\hline$P$ value* & 1.0 & 0.4 & 0.04 & 0.000 & 0.000 & 0.000 & 0.000 \\
\hline \multicolumn{8}{|l|}{ Sedation scores } \\
\hline Group PCA-A & $3(2-4)$ & $3(2-4)$ & $3(2-4)$ & $3(2-4)$ & $3(2-4)$ & $3(2-3)$ & $2(2-4)$ \\
\hline Group PCA-B & $3(2-3)$ & $3(3-4)$ & $3(2-4)$ & $3(2-4)$ & $2(2-4)$ & $2(2-4)$ & $2(2-3)$ \\
\hline$P$ value* & 1.0 & 0.1 & 1.0 & 0.6 & 0.6 & 1.0 & 1.0 \\
\hline \multicolumn{8}{|c|}{ Cumulative morphine consumption (mg) } \\
\hline Group PCA-A & $11(6-18)$ & $14(7-16)$ & $15(7-19)$ & $19(8-24)$ & $22(11-29)$ & $25(14-44)$ & $34(15-80)$ \\
\hline Group PCA-B & $10(7-13)$ & $12(8-17)$ & $16(14-22)^{*}$ & $22(15-26)^{*}$ & $27(17-33)^{*}$ & $36(25-48)^{*}$ & $61(41-80)^{*}$ \\
\hline$P$ value* & 0.27 & 0.64 & 0.034 & 0.018 & 0.003 & 0.000 & 0.000 \\
\hline
\end{tabular}

PCA $=$ patient-controlled analgesia. ${ }^{*} P<0.05$ between Group PCA-A and Group PCA-B by Mann-Whitney $\mathrm{U}$ test; $\dagger P<0.05$ vs baseline by Wilcoxon test. Data are presented as median (min-max).

TABLE III Incidence of side effects

\begin{tabular}{lll}
\hline & Group PCA-A $(n=25)$ & Group PCA-B $(n=25)$ \\
\hline Side effects & $n(\%)$ & $n(\%)$ \\
Nausea & $2(8.0)$ & $3(12.0)$ \\
Vomiting & $0(0)$ & $1(4.0)$ \\
Pruritus & $2(8.0)$ & $2(8.0)$ \\
\hline
\end{tabular}

PCA = patient-controlled analgesia. There was no statistical difference between groups.

opioid requirements (caused by pain from the sternotomy) and who must in any case be closely monitored.

Our study confirmed the beneficial effect of a background infusion; although the cumulative dose of morphine was increased, VRS scores were reduced. Pain relief was acceptable in both groups after the first postoperative hour, a similar number of patients in each group requiring supplemental bolus morphine. Tsang et al..$^{11}$ reported a lower VAS score $(<3)$ during the first postoperative hour after cardiac surgery with PCA morphine. An initial loading dose of morphine was followed by 1 or $2 \mathrm{mg}$ every 15 min until VAS < 3 was achieved. Thereafter patients used a standardized $1 \mathrm{mg}$ demand bolus with a lockout time of ten minutes. The continuous infusion rate was also set at $1 \mathrm{mg}$ per hour during the first $24 \mathrm{hr}$.

Tsang et al., after sufentanil anesthesia, used much smaller loading doses of PCA morphine (average $2.4 \pm$ $5.1 \mathrm{mg}$ ) than us, and yet achieved a VAS $<3$, a much better result than ours during the first postoperative hour. The lack of residual effect of propofol-remifentanil anesthesia may explain this difference. ${ }^{11}$ Our loading doses of morphine were $11.6 \pm 1.7 \mathrm{mg}$ in group PCA-A and 10.6 $\pm 2.2 \mathrm{mg}$ in group PCA-B, yet VRS scores exceeded 5 during the first postoperative hour in both groups. Dal et $a l .{ }^{15}$ also used smaller loading and bolus doses of morphine than ours. Their PCA included a 3-mg loading dose of morphine, and a 1-mg bolus dose with a 15-min lockout period. Thus our loading doses of morphine were greater, VRS scores at the first hour were similar, but were lower thereafter in both groups in our study.

Adding a background infusion to a morphine PCA may increase cumulative morphine consumption without improving pain relief, ${ }^{3,4,16,17}$ but in our study, VRS scores decreased after the first hour. Two recent studies reported cumulative morphine consumption as $29 \mathrm{mg}$ and $35.99 \mathrm{mg}$ for $24 \mathrm{hr}$ in cardiac surgery patients. ${ }^{18,19}$ Dal et al. reported a mean cumulative morphine consumption for PCA plus infusion of $32.8 \mathrm{mg}$, and 18.5 mg without infusion, for the first $24 \mathrm{hr} .{ }^{15}$ We too found a greater cumulative morphine consumption and lower VRS scores with the background infusion, but similar sedation scores in the two groups.

Respiratory depression, the most important side effect of morphine PCA, may be more common (1.1 to $3.9 \%$ incidence) when a background infusion is added. ${ }^{20,21}$ Morphine $20 \mu \mathrm{g} \cdot \mathrm{kg}^{-1} \cdot \mathrm{hr}^{-1}$ significantly increases the incidence of respiratory depression, sedation, nausea and vomiting. ${ }^{17}$ However, a background infusion of morphine $0.5 \mathrm{mg} \cdot \mathrm{hr}^{-1}$ produced no significant respiratory depression in patients extubated after cardiac surgery. ${ }^{15}$ We used $30 \mu \mathrm{g} \cdot \mathrm{kg}^{-1} \cdot \mathrm{hr}^{-1}$, and observed no respiratory depression or hypoxemia. Our two groups suffered similar incidences of nausea; other side effects (cough suppression, urinary retention, and constipation) were mostly minor. 
Finally, effective pain relief requires flexible dosage, the ability to deliver the dose to the patient truly "on demand," and regular monitoring of the adequacy of analgesia and of any drug-related side effects. PCA with a background infusion can be used effectively and safely in cardiac surgery patients who, in any case, require close observation. However, in this patient population, PCA instructions may need to be repeated during the early postoperative period because of incomplete recovery of higher cognitive function and disorientation in the ICU environment.

We conclude that, in patients extubated in the operating room after coronary artery bypass surgery, the addition of a background morphine infusion to morphine PCA increases morphine consumption and improves pain relief, without increasing side effects.

\section{Acknowledgements}

The authors gratefully acknowledge the assistance of cardiovascular care unit nursing staff and would like to thank G. Seydaoglu, PhD, for expert statistical advice. The study was not supported by external funds.

\section{References}

1 Lee TW, Jacobsohn E. Pro: Tracheal extubation should occur routinely in the operating room after cardiac surgery. J Cardiothorac Vasc Anesth 2000; 14: 603-10.

2 Gust R, Pecher S, Gust A, Hoffmann V, Bobrer H, Martin E. Effect of patient-controlled analgesia on pulmonary complications after coronary artery bypass grafting. Crit Care Med 1999; 27: 2218-23.

3 O'Connor CJ. Pain relief and pulmonary morbidity after cardiac surgery. Crit Care Med 1999; 27: 2314-6.

4 Checketts MR, Gilhooly CJ, Kenny GN. Patient-maintained analgesia with target-controlled alfentanil infusion after cardiac surgery: a comparison with morphine PCA. Br J Anaesth 1998; 80: 748-51.

5 Macintyre PE. Safety and efficacy of patient-controlled analgesia. Br J Anaesth 2001; 87: 36-46.

6 Walder B, Schafer M, Henzi I, Tramer MR. Efficacy and safety of patient-controlled opioid analgesia for acute postoperative pain. A quantitative systematic review. Acta Anaesthesiol Scand 2001; 45: 795-804.

7 Lam KK, Chan MT, Chen PP, Kee WD. Structured preoperative patient education for patient-controlled analgesia. J Clin Anesth 2001; 13: 465-9.

8 Myles PS, Buckland MR, Cannon GB, et al. Comparison of patient-controlled analgesia and nursecontrolled infusion analgesia after cardiac surgery. Anaesth Intensive Care 1994; 22: 672-8.

9 Pettersson PH, Lindskog EA, Öwall A. Patient-controlled versus nurse-controlled pain treatment after coronary artery bypass surgery. Acta Anaesthesiol
Scand 2000; 44: 43-7.

10 Boldt J, Thaler E, Lehmann A, Papsdorf M, Isgro F. Pain management in cardiac surgery patients: comparison between standard therapy and patient-controlled analgesia regimen. J Cardiothorac Vasc Anesth 1998; 12: 654-8.

11 Tsang J, Brush B. Patient-controlled analgesia in postoperative cardiac surgery. Anaesth Intensive Care 1999; 27: 464-70.

12 Rapanos T, Murphy P, Szalai JP, Burlacoff L, LamMcCulloch J, Kay J. Rectal indomethacin reduces postoperative pain and morphine use after cardiac surgery. Can J Anesth 1999; 46: 725-30.

13 Searle NR, Roy M, Bergeron G, et al. Hydromorphone patient-controlled analgesia (PCA) after coronary artery bypass surgery. Can J Anaesth 1994; 41: 198-205.

14 Ramsay MA, Savege TM, Simpson BR, Goodwin R. Controlled sedation with alphaxolone-alphadolone. $\mathrm{Br}$ J Med 1974; 2: 656-9.

15 Dal D, Kanbak M, Caglar M, Aypar U. A background infusion of morphine does not enhance postoperative analgesia after cardiac surgery. Can J Anesth 2003; 50: 476-9.

16 Dawson PJ, Libreri FC, Jones DJ, Libreri G, Bjorkstein $A R$, Royse CF. The efficacy of adding a continuous intravenous morphine infusion to patient-controlled analgesia (PCA) in abdominal surgery. Anaesth Intensive Care 1995; 23: 453-8.

17 Doyle E, Harper I, Morton NS. Patient-controlled analgesia with low dose background infusions after lower abdominal surgery in children. Br J Anaesth 1993; 71: 818-22.

18 Munro AJ, Long GT, Sleigh JW. Nurse-administered subcutaneous morphine is a satisfactory alternative to intravenous patient-controlled analgesia morphine after cardiac surgery. Anesth Analg 1998; 87: 11-5.

19 Zimmermann AR, Kibblewhite D, Sleigh J. Comparison of morphine/droperidol and tramadol/droperidol mixture for patient controlled analgesia (PCA) after cardiac surgery: a prospective, randomised, double-blind study. Acute Pain 2002; 4: 65-9.

20 Schug SA, Torrie JJ. Safety assessment of postoperative pain management by an acute pain service. Pain 1993; 55: 387-91.

21 Smythe MA, Zak MB, O'Donnell MP, Schad RF, Dmuchowski CF. Patient-controlled analgesia versus patient-controlled analgesia plus continuous infusion after hip replacement surgery. Ann Pharmacother 1996; 30: 224-7. 